\title{
Magnitude of Severe Head Injury and Its Associated Factors among Head Injury Patients in Gedeo Zone, Southern Ethiopia: A Two-Year Retrospective Study
}

\author{
Akine Eshete $^{1^{*}}$, Fikirewold Taye ${ }^{2}$
}

\author{
OPEN ACCESS \\ Citation: Akine Eshete,, Fikirewold Taye. \\ Magnitude of Severe Head Injury and Its \\ Associated Factors among Head Injury \\ Patients in Gedeo Zone, Southern Ethiopia: \\ A Two-Year Retrospective Study. Ethiop J \\ Health Sci.2018;28(3): 323. \\ doi:http://dx.doi.org/10.4314/ejhs.v28i3.10 \\ Received: December 6, 2017 \\ Accepted: December 6, 2017 \\ Published: May 1, 2018 \\ Copyright: (C) 2018 Akine Eshete, et al . \\ This is an open access article distributed \\ under the terms of the Creative Commons \\ Attribution License, which permits \\ unrestricted use, distribution, and \\ reproduction in any medium, provided the \\ original author and source are credited. \\ Funding: Nil \\ Competing Interests: The authors declare \\ that this manuscript was approved by all \\ authors in its form and that no competing \\ interest exists. \\ Affiliation and Correspondence: \\ ${ }^{1}$ School of Public health, College of \\ Health Sciences and Medicine, Dilla \\ University, Ethiopia \\ ${ }^{2}$ Departments of Obstetrics and \\ Gynecology, College of Health \\ Sciences and Medicine, Dilla \\ University, Ethiopia \\ *Email: akine.eshete@yahoo.com
}

\section{ABSTRACT}

BACKGROUND: Severe head injury is a major public health threat that is the main cause of morbidity and mortality in all age groups of the world's populations including Ethiopia. In view of this, this study was assessed the severity of head injury and its contributing factors. METHODS: $A$ Two-year retrospective study was conducted at Dilla University Referral Hospital, from December 2014 to November 2016. All head injury patients admitted to the surgical ward were included. Bivariate and multivariate regression analyses were used to identify factors associated with severity of head injury.

RESULTS: A total of 106 eligible head injury patient charts were reviewed. The magnitude of severe head injury was 32.1\%. Young populations, mainly males, were the highest risk groups, and road traffic accident was the main cause of severe head injury. In adjusted analysis, age interval greater than 45 years (aOR, 5.41; 95\% CI:1.0529.09), alcohol consumption before the trauma (aOR, 4.16, 95\%CI: $1.18,14.61$ ), delayed presentation (beyond 24 hours) after injury (aOR, 4.717; 95\% CI: 1.02-21.81), and respiratory rate greater than 30 breaths per minute (aOR, 7.34; 95\% CI: 1.88-28.73) were significantly associated with severe head injury.

CONCLUSIONS: Severe head injury remains an important public health problem. Young adults were the highest risk groups of populations. Prevention of road traffic accidents, continuous awareness creation about the consequences of road traffic accident and close neurological monitoring offered by neuro-intensive care unit are recommended.

KEYWORDS: Head Injury, Glasgow Coma Scale, Severe Head Injury

\section{INTRODUCTION}

Severe head injury is nowadays a major public health threat that is the main cause of morbidity and mortality in all age groups in the world's populations including Ethiopia. Even if sever traumatic head injury is common in young populations mainly in males (1-3), mortality associated with severe head injury was higher in all age groups (4-6). Head injury was mild in the majority of head injury victims followed by severe and moderate based on Glasgow Coma Scale (GCS) score $(7,8)$.

Patients who died of head injury were more significantly associated with lower GCS and more 
likely to develop higher incidence of infection and sepsis compared to mild or moderate head injury patients $(3,9-11)$

Severe head injury associated with road traffic accident (RTA) is a leading cause of death, particularly in African countries including Ethiopia. Worldwide, 1.25 million people died in relation to RTAs, mainly in sub-Saharan Africa (27 deaths per 100,000 people compared to 17 deaths per 100,000 people worldwide) and now a day RTA is the agenda of Sustainable Development Goals $(12,13)$.

Head injury is a significant public health problem in Ethiopia and one of the most common reasons for emergency department visit with admission increasing from time to time $(6,14)$. Like in other countries, in Ethiopia, the most common identified risk factors for severe head injuries were RTA, interpersonal violence and falling accidents $(15,16)$.

Even if the government of Ethiopia has developed policies and strategies to minimize road traffic accidents, morbidity and mortality associated with severe head injury as result of RTAs are still very high. For example a study done in Ethiopia, nearly three fourth $(66.7 \%)$ of patients were sustained severe head injury and $5.9 \%$ were died among severe head injury patients (16). The finding of another study also indicated that a significant number of head injury patients manifested incidence of severe head injury (6).

To the knowledge of the researchers, severe head injury with its risk factors was mostly affecting the productive age group populations in Ethiopia. A clearer understanding of the causes and outcome of these patients is essential for establishment of preventive strategies and treatment protocols. Such data is limited in Ethiopia, and also was no research conducted in the study area. Therefore, this study aimed to fill the gap by estimating the magnitude of severe head injury and its associated factors among admitted patients in Dilla University Referral Hospital.

\section{MATERIALS AND METHODS}

Institutional based retrospective study was conducted from December 2014 to November 2016 at Dilla University Referral Hospital. In Gedeo Zone, it serves as the referral hospital for the surrounding dwellers. Patients with head injury admitted to surgical ward were included. Head injury patients' charts that had 20 percent inadequate data, lost from record office due to consultation transfer or any other medical reason and patients who died within six hours after admission were excluded from the study (Figure 1).

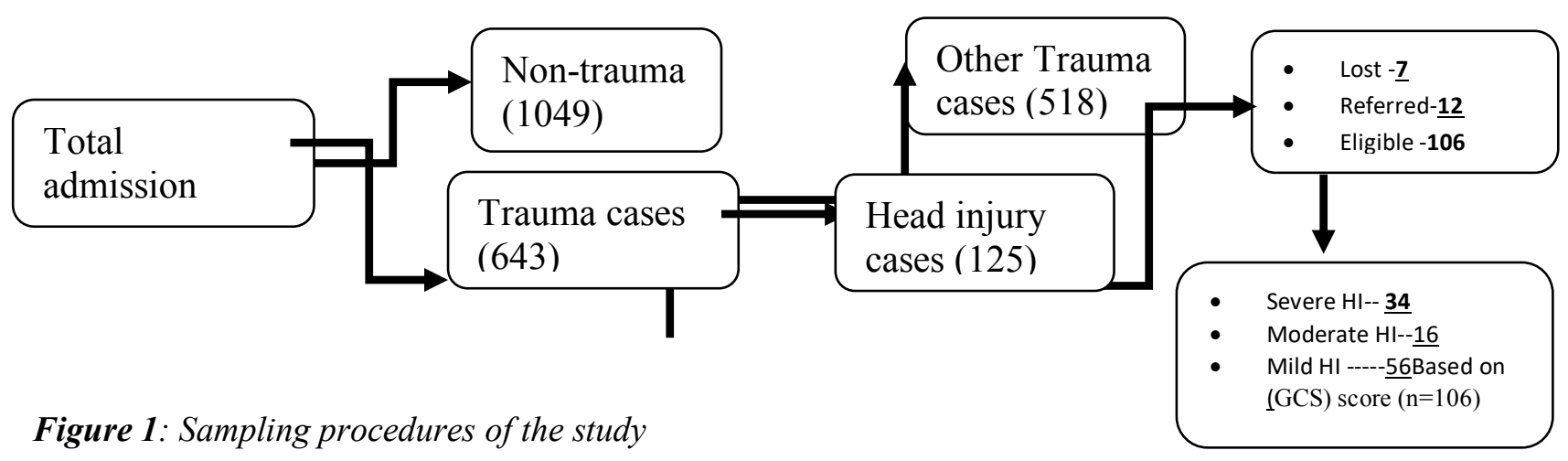

Data were collected from eligible patient charts from surgical ward logbook and health management information system unit. Review checklists adopted from previous research works $(15,16)$.

Severity of head injury was the primary outcome of this study. Severity of head injury was measured with Glasgow Coma Scale (GCS) score.

The GCS focuses on the importance of central nervous system function that consists verbal, motor, and eye-opening responses. The overall score was classified as mild (score:13-15), moderate (score:9-12) or severe $($ score: $<9)(7,8)$. 
Table 1: Measure of Glasgow Coma Scale score among admitted head injury patients in Dilla University Referral Hospital, from December 2014 to November 2016 G.C.

\begin{tabular}{|c|c|c|c|c|c|}
\hline Eye opening & Score & Verbal response & Score & Best motor response & Score \\
\hline Spontaneous & 4 & Oriented & 5 & Obeys command & 6 \\
\hline To speech & 3 & Confused & 4 & Localizes pain & 5 \\
\hline To pain & 2 & Inappropriate words & 3 & Withdraws & 4 \\
\hline \multirow[t]{2}{*}{ Nil } & 1 & Incomprehensive sound & 2 & Abnormal flexion & 3 \\
\hline & & Nil & 1 & Abnormal extension & 2 \\
\hline
\end{tabular}

For the ease of logistic regression analysis, the outcome variable was dichotomized into a score of GCS $\geq 9$ as 'not severe head injury' and score of GCS $<9$ as "severe head injury". The secondary outcome of this study was the outcome of severe head injury. Outcome of severe head injury (i.e. dead or alive) was measured basedon the patients' condition (i.e. dead or alive) at the end of their hospital stay. Data about patient demographics, mechanism of injury that leads to sever head injury, duration and place of injury, type of head injury (open/closed) and co-morbidity diseases were extracted from patient history charts.

Data were entered and cleaned using Epi INFO vision 7 and exported to SPSS V-20 for analysis. Descriptive statistics were run to see the overall distribution of the study variables. Logistic regression analysis was used to identify factors associated with severity of head injury. Finally, multivariate analysis was applied to control for possible confounding factors and to identify independent predictor(s) of severe head injury. A significance level at $\alpha \leq 0.05$ was used to decide statistical significance.

Ethical approval was obtained from Dilla University, College of Health Sciences and Medicine. Permission was secured from all concerned administrators. Issues of confidentiality were maintained by removing any identifiers from the questionnaire.

\section{RESULTS}

Socio-demographic characteristics of study participants: A total of 106 eligible head injury patient records were reviewed. The mean $( \pm \mathrm{SD})$ age of patients was $24.74 \pm 15.84$ years. The majority of head injury patients were found in the age categories of $15-29$ years $(36.8 \%)$, and under 15 years (29.2\%). Theyalso came from rural areas $(55.7 \%)$. There was a male dominance of head injury patients $(71.7 \%)$. Fifty-eight (54.7\%) patients were referred from public health center (Table 2).

Table 2: Socio-demographic characteristics of the study subjects in Dilla University Referral Hospital, from December 2014 to November 2016 G.C.

\begin{tabular}{lll}
\hline Variables & Category & Frequency (\%) \\
\hline Sex & Male & $76(71.7)$ \\
& Female & $30(28.3)$ \\
Age in years & $<15$ years & $31(29.2)$ \\
& $15-29$ years & $39(36.8)$ \\
& $30-45$ years & $19(17.9)$ \\
Residence & $>45$ years & $17(16.0)$ \\
Source of referral & Rural & $59(55.7)$ \\
& Urban & $47(44.3)$ \\
& Public health center & $58(54.7)$ \\
& Public hospital & $11(10.4)$ \\
& Private health institution & $6(5.7)$ \\
& Self-referral/direct presentation/ & $31(29.2)$ \\
\hline
\end{tabular}

DOI: http://dx.doi.org/10.4314/ejhs.v28i3.10 
Severity of head injury among admitted head injury patients: Out of the 106 head injury patients, 34 sustained severe head injury, making a proportion of $32.1 \%$, with the majority $(82.4 \%)$ being males. More than half, $(52.8 \%)$, were mild head injury and the remaining (15.1\%) were moderate head injury. Patients with the age categories greater than 45 yours old had more developed severe head injury 10(34.4\%) followed by age categories less than 15 years old $9(26.5 \%)$ (Table 3).

Table 3: Severe head injury among admitted head injury patients in Dilla University Referral Hospital, from December 2014 to November 2016 G.C.

\begin{tabular}{|c|c|c|c|c|c|}
\hline \multirow[t]{2}{*}{ Variable } & \multirow[t]{2}{*}{ Category } & \multicolumn{3}{|c|}{ Severity of head injury } & \multirow[t]{2}{*}{$\mathrm{n}(\%)$} \\
\hline & & Mild & Moderate & Severe & \\
\hline \multirow[t]{3}{*}{ Sex } & Male & 38 & 10 & 28 & $76(71.7)$ \\
\hline & Female & 18 & 6 & 6 & $30(28.3)$ \\
\hline & Total & 56 & 16 & 34 & $106(100)$ \\
\hline \multirow[t]{5}{*}{ Age } & $<15$ years & 14 & 8 & 9 & $31(29.2)$ \\
\hline & $15-29$ years & 27 & 5 & 7 & $39(36.8)$ \\
\hline & $30-45$ years & 10 & 1 & 8 & 19(17.9) \\
\hline & $>45$ years & 5 & 2 & 10 & $17(16)$ \\
\hline & Total & 56 & 16 & 34 & $106(100)$ \\
\hline
\end{tabular}

Mechanisms and characteristics of severe head injury: Road traffic accident (44.1\%) was the main cause of severe head injury. The median time for patients to reach the hospital after injury was 9.50 hours (with range of 1-48 hours). The majority, (35.5\%), of the severe head injury patients delayed more than 24 hours since trauma, and about $(61.8 \%)$ of patients with severe head injury had blunt skull trauma (Table 4).

Management and outcome of severe head injury patients: Of the total of cases, 33(31.1\%) had diagnosis with basal skull fracture, of which $12(36.4 \%)$ were severe head injury patients. Among severe head injury patients, $(61.8 \%)$ were managed conservatively, and the remaining $(38.2 \%)$ underwent operative procdure and about $(47.1 \%, \mathrm{n}=16)$ stayed between $5-10$ days in the hospital. The median stay of patients was five days (with range of 1-19 days). Mortality was higher among patients with severe head injury, (235\% per 1000 populations, $n=34)$ compared to the total cases $(113 \%$ per 1000 population, $n=106$ ) (Table 4).

Factors associated with severe head injury among admitted head injure patients: In bivariate analysis, age of the respondents, source of referral, alcohol consumption before trauma, duration of injury, respiratory and pulse rate at presentation and length of hospital stay following trauma had significant associations with severe head injury (Table 5). Variables which were found to be significant $(\mathrm{p} \leq 0.05)$ at bi-variate analysis were further entered into a multivariate model to identify the independent factors of severe head injury.

In adjusted analysis, patients with age greater than 45 years old tend to have severe head injury aOR,5.41; 95\% CI:1.05-29.09) compared to age less than 15 years old. Patients who consumed alcohol before trauma were four times more vulnerable to have severe head injury than patients who did not use alcohol (aOR,4.16; 95\% CI: 1.1814.61).

Delayed presentation (beyond 24 hours) after injury and patient stay of more than five days were associated with a great risk of having severe head injury (aOR, 4.717; 95\% CI: 1.02-21.81), and (aOR, 2.88; 95\% CI:1.02-8.66), respectively. Greater than 30 breaths per minute respiratory rate at presentation also had a significant association with severe head injury (aOR, 7.34; 95\% CI: 1.88-28.73). Other variables like source of referral, pulse rate at presentation and having complication of head injury did not show an association

DOI: http://x.doi.org/10.4314/ejhs.v28i7.10 
with severe head injury in multivariate analysis (Table

6).

Table 4: Diagnosis, management, mechanisms and characteristics of injury among admitted head injury patients in Dilla University Referral Hospital, from December 2014 to November 2016 G.C.

\begin{tabular}{|c|c|c|c|c|}
\hline \multirow[t]{2}{*}{ Variables } & \multirow[t]{2}{*}{ Category } & \multicolumn{2}{|c|}{ Severity of head injury } & \multirow[t]{2}{*}{ N (\%) } \\
\hline & & Not severe \# & Severe & \\
\hline \multirow[t]{4}{*}{ Mechanism of injury } & Road traffic accident & 27 & 15 & $42(39.6)$ \\
\hline & Interpersonal violence & 28 & 7 & $35(33.0)$ \\
\hline & Fall down accident & 14 & 7 & $21(19.8)$ \\
\hline & Others $\$$ & 3 & 5 & $8(7.5)$ \\
\hline \multirow{2}{*}{ Type of injury } & Open(penetrating) & 28 & 13 & $41(38.7)$ \\
\hline & Closed(blunt) & 44 & 21 & $65(61.3)$ \\
\hline \multirow{2}{*}{$\begin{array}{l}\text { Alcohol consumption before } \\
\text { injury }\end{array}$} & Yes & 14 & 15 & $29(27.4)$ \\
\hline & No & 58 & 19 & $77(72.6)$ \\
\hline \multirow{2}{*}{$\begin{array}{l}\text { Means of transportation to } \\
\text { hospital }\end{array}$} & Ambulance & 41 & 23 & $64(60.4)$ \\
\hline & Others* & 31 & 11 & $42(39.6)$ \\
\hline \multirow{4}{*}{ Time elapsed since trauma } & $<6$ hours & 26 & 7 & $33(31.1)$ \\
\hline & 6-12 hours & 23 & 9 & $32(30.2)$ \\
\hline & $12-24$ hours & 16 & 6 & $22(20.8)$ \\
\hline & $>24$ hours & 7 & 12 & 19(17.9) \\
\hline \multirow[t]{5}{*}{ Type of diagnosis } & No other diagnosis & 13 & 7 & $20(18.9)$ \\
\hline & Scalp laceration & 19 & 4 & $23(21.7)$ \\
\hline & Linear skull fracture & 3 & 4 & $7(6.6)$ \\
\hline & Depressed skull fracture & 16 & 7 & $23(21.7)$ \\
\hline & Basal skull fracture & 21 & 12 & $33(31.1)$ \\
\hline \multirow[t]{2}{*}{ Other body part injury $\$ \$$} & Yes & 11 & 7 & $18(17.0)$ \\
\hline & No & 61 & 27 & $88(83.0)$ \\
\hline \multirow[t]{2}{*}{ Management given } & Conservative & 67 & 21 & $88(83.0)$ \\
\hline & Operative & 5 & 13 & $18(17.0)$ \\
\hline \multirow[t]{3}{*}{ Hospital stay } & $<5$ days & 45 & 14 & $59(55.7)$ \\
\hline & 5-10 days & 25 & 16 & $41(38.7)$ \\
\hline & $>10$ days & 2 & 4 & $6(5.8)$ \\
\hline \multirow[t]{6}{*}{ Type of complications } & No complication & 56 & 20 & $76(71.7)$ \\
\hline & Infection & 2 & 0 & $2(1.9)$ \\
\hline & Seizure & 6 & 7 & $13(12.3)$ \\
\hline & Increased ICP & 1 & 0 & $1(0.9)$ \\
\hline & Anemia & 6 & 5 & $11(10.4)$ \\
\hline & Seizure \& anemia & 1 & 2 & $3(2.8)$ \\
\hline \multirow[t]{2}{*}{ Management outcome } & Improved\& discharged & 68 & 26 & $94(88.7)$ \\
\hline & Died & 4 & 8 & $12(11.3)$ \\
\hline
\end{tabular}

Others \$ includes, kicked by anima; not severe \# includes mild and moderate; others* includes, public transport, motor bicycle, automobile, on foot and traditional ambulance, \$\$ includeschest, abdomen, pelvic injury and long bone fracture

\section{DISCUSSION}

In this study, the incidence of severe head injury was $32.1 \%$, which was consistent with the previous findings in Tanzania $(32 \%)$ and northern Nigeria $(33.8 \%)(4,10)$ and higher than a study done in Jimma Specialized Hospital (14.8\%) (16). This study indicates (15.1\%) and $(52.8 \%)$ patients who were admitted to surgical ward had moderate and mild head injury respectively, which was similar to studies done in Nigeria (4) and in Jimma University Specialized Hospital-Ethiopia (16). The findings indicate that till today a significant number of head injury patients were suffering from severe head injury that needs a close neurological

DOI: http://dx.doi.org/10.4314/ejhs.v28i3.10 
Table 5: Bi-variate analysis with severe head injury among admitted head injury patients in Dilla University Referral Hospital, from December 2014 to November 2016 G.C.

\begin{tabular}{|c|c|c|c|c|}
\hline \multirow[t]{2}{*}{ Variables } & \multicolumn{2}{|c|}{ Severity of head injury } & \multirow[t]{2}{*}{ P-value } & \multirow[t]{2}{*}{$\operatorname{COR}(95 \% \mathrm{CI})$} \\
\hline & Not severe & Severe & & \\
\hline \multicolumn{5}{|l|}{ Sex of the patients } \\
\hline Male & 48 & 28 & & 1.00 \\
\hline Female & 24 & 6 & 0.100 & $0.42(0.16-1.18)$ \\
\hline \multicolumn{5}{|l|}{ Age categories of the patients } \\
\hline$<15$ years & 22 & 9 & & 1.00 \\
\hline 15-29 years & 32 & 7 & 0.276 & $0.54(0.17-1.65)$ \\
\hline $30-44$ years & 11 & 8 & 0.346 & $1.77(0.54-5.88)$ \\
\hline$>45$ years & 7 & 10 & 0.048 & $3.49(1.02-12.05)$ \\
\hline \multicolumn{5}{|l|}{ Residence of patients } \\
\hline Rural & 42 & 17 & & 1.00 \\
\hline Urban & 30 & 17 & 0.421 & $1.40(0.62-1.18)$ \\
\hline \multicolumn{5}{|l|}{ Source of referral } \\
\hline Public health center \& Hospital & 42 & 27 & & 1.00 \\
\hline Direct presentation and private clinic & 30 & 7 & 0.037 & $0.36(0.14-0.94)$ \\
\hline \multicolumn{5}{|l|}{ Mechanism of injury } \\
\hline RTA & 27 & 15 & & 1.00 \\
\hline Interpersonal violence & 28 & 7 & 0.133 & $0.45(0.16-1.28)$ \\
\hline Others ${ }^{*}$ & 17 & 12 & 0.629 & $1.27(0.48-3.34)$ \\
\hline \multicolumn{5}{|l|}{ Type of head injury } \\
\hline Open(penetrating) & 28 & 13 & 0.949 & $0.97(0.42-2.25)$ \\
\hline Closed(blunt) & 44 & 21 & & 1.00 \\
\hline \multicolumn{5}{|l|}{ Alcohol consumption before injury } \\
\hline Yes & 14 & 15 & 0.009 & 3.27(1.34-7.99) \\
\hline No & 58 & 19 & & 1.00 \\
\hline Means of transportation & & & & \\
\hline Ambulance & 41 & 23 & & 1.00 \\
\hline Others $^{\#}$ & 31 & 11 & 0.295 & $0.63(0.27-1.49)$ \\
\hline \multicolumn{5}{|l|}{ Time elapsed since injury } \\
\hline$<6$ hours & 26 & 7 & & 1.00 \\
\hline 6-12 hours & 23 & 9 & 0.519 & $1.45(0.48-4.53)$ \\
\hline $12-24$ hours & 16 & 6 & 0.605 & $1.39(0.39-4.89)$ \\
\hline$>24$ hours & 7 & 12 & 0.004 & $6.36(1.82-22.25)$ \\
\hline $\begin{array}{c}\text { Pulse rate at presentation } \\
600-90 \mathrm{BPM}\end{array}$ & 50 & 13 & & 1.00 \\
\hline$\geq 90 \mathrm{BPM}$ & 22 & 21 & 0.003 & $3.67(1.56-8.63)$ \\
\hline \multicolumn{5}{|l|}{ Respiratory rate at presentation } \\
\hline $10-30$ breath per minute & 62 & 22 & & 1.00 \\
\hline $\begin{array}{l}>30 \text { breath per minute } \\
\text { Injury to other body part }\end{array}$ & 10 & 12 & 0.014 & $3.38(1.28-8.92)$ \\
\hline Yes & 11 & 7 & 0.498 & $1.44(0.503-4.11)$ \\
\hline \multirow{2}{*}{\multicolumn{5}{|c|}{ Length of Hospital stay }} \\
\hline & & & & \\
\hline$<5$ days & 45 & 14 & & 1.00 \\
\hline$>5$ days & 27 & 20 & 0.041 & $2.38(1.04-5.48)$ \\
\hline \multicolumn{5}{|l|}{ Complication of head injury } \\
\hline Yes & 16 & 14 & 0.046 & $2.45(1.02-5.91)$ \\
\hline No & 56 & 20 & & 1.00 \\
\hline
\end{tabular}

Others* includes, fall down accident and kicked by anima; others \# includes, traditional ambulance, on foot, public transport, motor bicycle, automobile

DOI: http://dx.doi.org/10.4314/ejhs.v28i7.10 
Table 6: Multivariate analysis with severe head injury among admitted head injury patients in DURH, from December 2014 to November 2016 G.C

\begin{tabular}{|c|c|c|}
\hline Variables & P-values & aOR (95\% CI ) \\
\hline \multicolumn{3}{|l|}{ Age of the patient } \\
\hline$<15$ years & & 1.00 \\
\hline $15-29$ years & 0.685 & $0.72(0.150-3.483)$ \\
\hline $30-44$ years & 0.826 & $1.22(0.205-7.282)$ \\
\hline$>45$ years & 0.049 & $5.40(1.05-29.09)$ * \\
\hline \multicolumn{3}{|c|}{ Alcohol consumption before injury } \\
\hline Yes & 0.026 & $4.15(1.18-14.61) *$ \\
\hline No & & 1.00 \\
\hline \multicolumn{3}{|c|}{ Time elapsed since injury before presentation } \\
\hline$<6$ hours & & 1.00 \\
\hline $6-12$ hours & 0.699 & $1.31(0.339-5.022)$ \\
\hline 12-24 hours & 0.823 & $1.19(0.247-5.817)$ \\
\hline$>24$ hours & 0.047 & 4.72(1.020-21.811)* \\
\hline \multicolumn{3}{|c|}{ Respiratory rate at presentation } \\
\hline $10-30$ breath/minute & & 1.00 \\
\hline$>30 \mathrm{breath} /$ minute & 0.004 & 7.34 (1.877-28.73)* \\
\hline \multicolumn{3}{|l|}{ Length of Hospital stay } \\
\hline$<5$ days & & \\
\hline$>5$ days & 0.060 & $2.88(1.021-8.660)$ \\
\hline
\end{tabular}

NB: Adjusted variables, were source of referral, pulse rate at presentation and having complication of head injury

monitoring offered by neuro-intensive care unit (NICU), particularly in the study area there is a need to establish functional neurosurgery department with NICU so as to manage such cases.

Severe head injury was higher in the age category of greater than 45 yours old (34.4\%) followed by age categories less than 15 years old $(26.5 \%)$. There was a male dominance of severe head injury patients $(82.4 \%)$. The difference among the age groups and gender may be due to the difference of factors such as mechanisms of transportations and risky behavior particularly alcohol consumption. Motor bicycle (vehicle) is the most common means of transportation in the study area. As results of such high-risk activity, economically active age group populations, particularly males were the main victims of head injury. And also affect the productivity of the country including individual in community.

The commonest cause of severe head injury in this study was RTA (44.1\%), which was similar with studies done in Ethiopia and abroad $(3,5,16)$. In this study, road traffic accidents (RTAs) increased the risk of having severe head injury, which needs awareness creation for the community and enforce driver rules and regulations in the area. Preventive measures which related to traffic safety rules and regulations, educational campaign on RTAs may reduce to the admission of patients related to head injury.

Mortality was higher among severe head injury patients (235\% per 1000 populations, $n=34$ ) compared to the total samples $(113 \%$ per 1000 population, $\mathrm{n}=106)$. This may be due to the management of cases. Most $(61.8 \%)$ of severe head injury cases were managed conservatively and also the majority $(35.5 \%)$ of severe head injury cases delayed more than 24 hours since trauma. In addition, without advanced service, staying more days in the hospital may increase the risk of dying. In this study, about $47.1 \%$ of severe head injury patients stayed between 5-10 days in the hospital. Therefore, this study alerts the concerned bodies for establishment of functional neurosurgery department and strengthen the referral systems.

Admitted patients aged greater than 45 years were more likely to have severe head injury compare to those aged less than 15 years, which was agreed than studies done in Spain (9) and in Sweden (7). Alcohol consumption before trauma increased the chance of having severe head injury compared to those who did not consumed alcohol, which was consistent the study conducted in Toronto, Canada (17).

Head injury patients who presented after 24 hours of the injury had nearly fivefold chances to develop severe head injury compared to those who presented with in six hours of the injury. In addition, having greater than 30 breaths per minute respiratory rates at presentation were associated with a great risk of having severe head injury in the study.

With the presence of some limitation in the study, the finding was generally consistent with those of studies in Ethiopia and abroad. In this study, only admitted patients at Dilla Referral Hospital were 
involved. These populations may not be representative of other hospitals in Ethiopia, and this may result in overestimating or underestimating the severity of head injury. However, this study estimates the prevalence of severe head injury and gives insights on the risk factors and high-risk activities that have direct relation with severe head injury.

In conclusion, the magnitude of severe head injury was $32.1 \%$. Young populations, mainly males, were the highest risk groups of populations and also a road traffic accident was the main cause of severe head injury in the study area. In adjusted analysis, age interval greater than 45 , alcohol consumption before the trauma, delayed presentation (beyond 24 hours) after injury, admission of greater than five days, and respiratory rate greater than 30 breaths per minute were significantly associated with severe head injury. Preventive measures which related to traffic safety rules and regulations and educational campaign on RTAs can may help to reduce the admission of patients related to head injury. Establishing neuro-intensive care unit in the health system will help to reduce the burden of severe head injury.

\section{ACKNOWLEDGMENT}

We would like to acknowledge Dilla University Refrral Hospital record office staffs for their contribution in data collection process.

\section{REFERENCES}

1. Maas AI, Stocchetti N. Bullock R. Moderate and severe traumatic brain injury in adults. Lancet Neurol. 2008; 7:728-41.

2. Fente Beleudanyo Gbalipre, Odjugo Eretare Cliford. Pattern and outcome of management of head injury by general surgeons at the accident and emergency department of the Niger delta university teaching hospital okolobiri, bayelsa state of nigeria. PalgoJ.Med.Medical.Sci, 2014; 1(1):1.

3. Hoxha S. Demographic Profile and Pathological Patterns of Head Injury in Albania. The Open Access Journal of Science and Technology, 2014; 2:1.

4. Jasper US, Opara MC, Pyiki EB, Akinrolie O. The Epidemiology of Hospital-referred Head Injury in Northern Nigeria. Journal of Scientific Research \& Reports. 2014; 3(15): 2055-2064.

5. Agrawal D, Ahmed S, Khan S., Gupta D, Sinha S, Satyarthee GD. Outcome in 2068 patients of head injury: Experience at a level 1 trauma center in India. Asian J Neurosurgery.2016; 11(2):143-5.
6. Landes, M, Venugopal R, Berman S, Heffernan S, et al. Epidemiology, clinical characteristics and outcomes of head injured patients in an Ethiopian emergency center. Afr J Emerg Med,2017; (7):130-4, http://dx.doi.org/10.1016/j.afjem.2017.04.001.

7. Salottolo K, Levy AS, Slone DS, Mains CW. The Effect of Age on Glasgow Coma Scale Score in Patients with Traumatic Brain Injury. JAMA Surg. 2014; 149 (7):727-734.

8. Khalid Khanzada, Shahid Nawaz, Mohammad Siddiq, Riaz ur Rehman. Pattern of head injuries' in patients admitted in lady reading hospital, peshawar. KJMS; 2011;3(2):79-82.

9. Al-Kuwaiti A, Hefny AF, Bellou A, Eid HO, AbuZidan FM. Epidemiology of head injury in the United Arab Emirates. Turkish Journal of Trauma \& Emergency Surgery, 2012; 18 (3):213.

10. Kourbeti IS, Vakis AF, Papadakis JA, Karabetsos DA, et al. Infections in traumatic brain injury patients. ClinMicrobiol Infect.2012;18(4):359-64.

11. Catherine Lynch. The Epidemiology and Predictors of Worse Outcome for Traumatic Brain Injury Patients at Kilimanjaro Christian Medical Center. Duke Global Health Institute;2013:1-35.

12. World Health Organization. Projections of mortality and burden of disease from 2002 to 2030 (Deaths by Income Group), Geneva, Switzerland, 2002.

13. United Nations. Report of UN Secretary-General. The Sustainable Development Goals Report 2017.

14. Seid M, Azazh A, Enquselassie F, Yisma E. Injury characteristics and outcome of road traffic accident among victims at Adult Emergency Department of TikurAnbessa specialized hospital, Addis Ababa, Ethiopia: a prospective hospital based study. $B M C$ Emerg Med;2015:15: 10.doi: 10.1186/s12873-015.

15. Isabel Aenders, teshagerGashaw, Mathias Siebeck, Wolf Mutcher. "Head injury- Neglected public health problem". Afour-month prospective study at JUSH, Ethiopia. Ethiop J Health Sci, 2014: 24 (1): 27-37.

16. Indeshaw k, Biruk K. Pattern of head injury among patients presented to adult emergency department of jimma university teaching hospital, Ethiopia. 2015. Open Acess Theses and Dessertation. http://etd.aau.edu.et/dspace/handle/123456789/7552

17. Tien HC, Tremblay LN, Rizoli SB, Gelberg J, et al. Association between Alcohol and Mortality in Patients with Severe Traumatic Head Injury. Arch Surg.;141(12):1185-91. 